\title{
High-dose supplemental selenite to male Syrian hamsters fed hypercholesterolaemic diets alters Ldlr, Abcg8 and Npc1/1 mRNA expression and lowers plasma cholesterol concentrations
}

\author{
Johanne Poirier ${ }^{1}$, Kevin A. Cockell ${ }^{1,2,3}$, Kylie A. Scoggan ${ }^{2,3}$, W. M. Nimal Ratnayake ${ }^{2}$, \\ Hélène Rocheleau ${ }^{2}$, Heidi Gruber ${ }^{2}$, Eleonora Swist ${ }^{2}$, Philip Griffin ${ }^{2}$, Claude Gagnon ${ }^{2}$ and Stan Kubow ${ }^{1 *}$ \\ ${ }^{1}$ School of Dietetics and Human Nutrition, Macdonald Campus of McGill University, 21,111 Lakeshore, \\ Ste-Anne-de-Bellevue, QC, Canada HOX 3 V9 \\ ${ }^{2}$ Nutrition Research Division, Food Directorate, Health Products and Food Branch, Health Canada, Ottawa, \\ ON, Canada K1A OKO \\ ${ }^{3}$ Department of Biochemistry, Microbiology and Immunology, University of Ottawa, Ottawa, ON, Canada K1H 8M5 \\ (Submitted 15 February 2011 - Final revision received 14 September 2011 - Accepted 14 September 2011 - First published online 9 December 2011)
}

\section{Abstract}

The aim of the present study was to elucidate possible cholesterol-lowering mechanism(s) of high-dose supplemental Se in the form of selenite, a known hypocholesterolaemic agent. Male Syrian hamsters (four groups, ten per group) were fed semi-purified diets for 4 weeks containing $0 \cdot 1 \%$ cholesterol and $15 \%$ saturated fat with selenite corresponding to varying levels of Se: (1) Se $0 \cdot 15$ parts per million (ppm), control diet; (2) Se $0.85 \mathrm{ppm}$; (3) Se $1.7 \mathrm{ppm}$; (4) Se $3.4 \mathrm{ppm}$. Lipids were measured in the bile, faeces, liver and plasma. The mRNA expression of several known regulators of cholesterol homeostasis (ATP-binding cassette transporters $g 5$ ( $A b c g 5)$ and $g 8$ ( $A b c g 8$ ), 7-hydroxylase, 3-hydroxy-3-methylglutaryl-coenzyme A reductase, LDL receptor ( $L d L r)$ and Nieman-Pick C1-like 1 protein ( $N p c 1 l 1)$ ) were measured in the liver and/or jejunum. Oxysterols including 24-(S)-hydroxycholesterol, 25-hydroxycholesterol and 27-hydroxycholesterol (27-OHC) were measured in the liver. Significantly lower total plasma cholesterol concentrations were observed in hamsters consuming the low $(0.85 \mathrm{ppm})$ and high $(3.4 \mathrm{ppm})$ Se doses. The two highest doses of Se resulted in decreased plasma LDL-cholesterol concentrations and increased mRNA levels of hepatic $A b c g 8, L d l r$ and jejunal Ldlr. Higher hepatic 27-OHC and TAG concentrations and lower levels of jejunal Npc1l1 mRNA expression were noted in the 1.7 and $3.4 \mathrm{ppm}$ Se-treated hamsters. Overall, Se-induced tissue changes in mRNA expression including increased hepatic $A b c g 8$ and $L d l r$, increased jejunal $L d l r$ and decreased jejunal $N p c 1 l 1$, provide further elucidation regarding the hypocholesterolaemic mechanisms of action of Se in the form of selenite.

Key words: 27-Hydroxycholesterol: ATP binding cassette transporter g8: Niemann-pick C1-like 1 protein: Jejunum

The supplementation of Se in its various chemical forms has been associated with decreased plasma cholesterol concentrations in both human ${ }^{(1-4)}$ and rodent ${ }^{(5-17)}$ studies. To date, the molecular mechanisms underlying the hypocholesterolaemic effects of high-dose supplemental selenite have not been clearly defined. Feeding trials involving rodent models of hypercholesterolaemia have shown selenite supplementation to be associated with lowered mRNA abundance of hepatic 3-hydroxy-3-methylglutaryl-coenzyme A reductase $(\mathrm{HmgCr})^{(5)}$ and increased mRNA abundance of hepatic LDL receptor $(L d l r)^{(6)}$. To our knowledge, no studies have examined the impact of selenite supplementation on three key genes involved in the control of cholesterol absorption: the heterodimeric ATP-binding cassette transporters $g 5$ $(A b c g 5)$ and $g 8(A b c g 8)$ and Nieman-Pick C1-like 1 protein (Npc1l1) in the Syrian hamster, which is the rodent model most similar to humans with regards to cholesterol metabolism $^{(18,19)}$. The heterodimeric transporters Abcg5 and Abcg8 are responsible for sterol efflux from hepatocytes ${ }^{(20)}$ and enterocytes $^{(21)}$, whereas the transporter Npc1l1 is involved in cholesterol entry into the enterocyte ${ }^{(22)}$. Overexpression of hepatic and intestinal $A b c g 5$ and $A b c g 8$ and inactivation of

Abbreviations: 24(S)-OHC, 24-(S)-hydroxycholesterol; 25-OHC, 25-hydroxycholesterol; 27-OHC, 27-hydroxycholesterol; Abcg5, ATP-binding cassette transporters g5; Abcg8, ATP-binding cassette transporters g8; Cyp7a1, 7-hydroxylase; FC, free cholesterol; Gapdh, glyceraldehyde 3-phosphate dehydrogenase; GOI, gene of interest; HDL-C, HDL-cholesterol; Hmgcr, 3-hydroxy-3-methylglutaryl-coenzyme A reductase; LDL-C, LDL-cholesterol; $L d l r$, LDL receptor; Npc1l1, Nieman-Pick C1-like 1 protein; ppm, parts per million; TC, total cholesterol.

* Corresponding author: S. Kubow, fax +1 514398 7739, email stan.kubow@mcgill.ca 
$N p c 111^{(23)}$ are associated with plasma lipid-lowering effects in conjunction with lowered hepatic cholesterol concentrations, which are the surrogate markers for cholesterol absorption ${ }^{(24)}$.

Gene expression of $A b c g 5$ and $A b c g 8$ is responsive to cholesterol feeding ${ }^{(25)}$, which is also associated with increased oxysterol concentrations ${ }^{(26)}$. The feeding of a high-cholesterol diet to triple-knockout mice unable to synthesise 24-(S)hydroxycholesterol (24(S)-OHC), 25-hydroxycholesterol (25-OHC) and 27-hydroxycholesterol (27-OHC) failed to induce hepatic mRNA abundance of Abcg5 and Abcg8, which implicates these oxysterols as key in vivo regulators of the mRNA expression of the heterodimers ${ }^{(27)}$. To date, however, in vivo concentrations of endogenously occurring oxysterols have generally not been examined within feeding trials investigating the effects of dietary cholesterol on the Abcg 5 and $A b c g 8$ genes.

Therefore, the aim of the present study was to examine the dose-related effect of high-dose selenite supplementation in the Syrian hamster fed $0 \cdot 1 \%$ cholesterol and $15 \%$ saturated fat diets on hepatic and/or jejunal mRNA abundance of Abcg5, Abcg8 and Npc1l1 genes in relation to cholesterol concentrations in plasma, liver, bile and faeces. The effect of supplemental selenite on the mRNA abundance of key cholesterol metabolising genes, 7-hydroxylase (Cyp 7a1), Hmgcr and Ldlr was also investigated. A secondary aim was to investigate the hypocholesterolaemic effects of selenite on in vivo tissue concentrations of $24(S)$-OHC, $25-\mathrm{OHC}$ and $27-\mathrm{OHC}$ in relation to the hepatic and jejunal mRNA expression of the $\operatorname{Abcg} 5$ and Abcg8 genes.

\section{Materials and methods}

\section{Animals and diets}

A total of forty Syrian male hamsters, aged 9-10 weeks (approximate weight 110-120g), were purchased from Charles River Laboratories (St-Constant, QC, Canada). The hamsters were housed individually in the Animal Resources Division, Food Directorate of Health Canada (Ottawa, ON, Canada) in stainless-steel wire-bottom cages and acclimatised to laboratory conditions for $10 \mathrm{~d}$ while being fed a standard commercial chow diet. At the end of the acclimatisation period, hamsters were weighed and randomised to four groups of ten animals each and fed their respective test diets for 4 weeks (Table 1). The dietary levels of selenite were adjusted to four different levels which included: (1) Se 0.15 parts per million (ppm); (2) Se $0.85 \mathrm{ppm}$; (3) Se $1.7 \mathrm{ppm}$; (4) Se $3.4 \mathrm{ppm}$. The minimal level of Se of $0.15 \mathrm{ppm}$ in the basal diet conformed to National Research Council guidelines for Se of $0 \cdot 1 \mathrm{ppm}^{(28)}$. The highest supplemental level of Se $(3.4 \mathrm{ppm})$ was chosen on the basis of a previous study ${ }^{(9)}$, which demonstrated that hamsters can safely tolerate this level of Se supplementation. Chronic toxicity of Se was tested in the previous work, which found levels of dietary Se up to $10 \mathrm{ppm}$ to be non-toxic to Syrian hamsters ${ }^{(29-31)}$. Diets were obtained from Dyets, Inc. (Bethlehem, PA, USA) in pellet form in vacuum-packed bags, which were stored at $-20^{\circ} \mathrm{C}$ to prevent lipid auto-oxidation. Feed was provided on a daily basis (approximately $15 \mathrm{~g} / \mathrm{d}$, accurately weighed) and hamsters had free access to tap water.

Table 1. Composition of experimental diets $(\mathrm{g} / \mathrm{kg})^{\star}$

\begin{tabular}{|c|c|c|c|c|}
\hline Ingredients & Se $(0.15 \mathrm{ppm})$ & Se $(0.85 \mathrm{ppm})$ & Se (1.7ppm) & $\mathrm{Se}(3.4 \mathrm{ppm})$ \\
\hline Casein, vitamin-free & 160 & 160 & 160 & 160 \\
\hline Maize starch & $245 \cdot 5$ & $245 \cdot 3$ & $245 \cdot 1$ & $244 \cdot 8$ \\
\hline Sucrose & 200 & 200 & 200 & 200 \\
\hline Dextrose & 100 & 100 & 100 & 100 \\
\hline Cellulose & 50 & 50 & 50 & 50 \\
\hline $\mathrm{BF}+$ & 150 & 150 & 150 & 150 \\
\hline Safflower oilł & 16 & 16 & 16 & 16 \\
\hline Cholesterol, USP§ & 0.9 & 0.9 & 0.9 & 0.9 \\
\hline Mineral mix\| & 50 & 50 & 50 & 50 \\
\hline Vitamin mixף & 10 & 10 & 10 & 10 \\
\hline Choline bitartrate & 13 & 13 & 13 & 13 \\
\hline Sodium selenite & 0.03 & 0.2 & 0.4 & 0.7 \\
\hline Vitamin A palmitate & 4.5 & 4.5 & 4.5 & 4.5 \\
\hline$\alpha$-Tocopheryl acetate & 0.1 & 0.1 & 0.1 & 0.1 \\
\hline Metabolisable energy (MJ/kg) & $19 \cdot 2$ & $19 \cdot 2$ & $19 \cdot 2$ & $19 \cdot 2$ \\
\hline
\end{tabular}

ppm, Parts per million; BF, butterfat; USP, United States Pharmacopeia.

${ }^{*}$ All diets were formulated at McGill University and prepared in pellet form by Dyets, Inc.

†BF fatty acid composition is as follows (\% by weight) as per Dyets inspection report: $4: 0,3 \cdot 4 ; 6: 0,2 \cdot 0 ; 8: 0,1 \cdot 2 ; 10: 0,2 \cdot 7 ; 12: 0$, $3.0 ; 14: 0,10 \cdot 7,14: 1,1.6 ; 16: 0,28 \cdot 0 ; 16: 1,2.5 ; 18: 0,13.0 ; 18: 1,26 \cdot 8 ; 18: 2,2.5,18: 3,1.5,20: 0,1 \cdot 1$.

$\ddagger$ Safflower oil was added to prevent essential fatty acid deficiency. $\alpha$-Tocopherol concentration of safflower oil is $350 \mathrm{ppm}$ of $\alpha$-tocopherol, $180 \mathrm{ppm}$ of other tocopherols. Fatty acid profile of safflower oil included (\% by weight): 14:0, trace; 16:0, 6.9; 16:1, trace; $18: 0,2 \cdot 9 ; 18: 1,12 \cdot 2 ; 18: 2,78 \cdot 0 ; 18: 3$, trace.

$\S$ Cholesterol USP standard was added to BF $4.193 \mathrm{~g} / \mathrm{kg}$.

II The mineral mix was free of Se and was composed of $(\mathrm{g} / \mathrm{kg})$ : calcium carbonate 336.4; calcium phosphate, monobasic 285.0; magnesium oxide 2.9 ; potassium iodate $\left(10 \mathrm{mg} \mathrm{KIO}_{3} / \mathrm{g}\right) 0.8$; potassium phosphate, dibasic 40.8 ; $\mathrm{NaCl} 11.5$; cupric carbonate 0.1 ; cobalt chloride 0.1 ; sodium fluoride 0.002 ; ferric citrate 25.5 ; manganous carbonate 0.2 ; ammonium paramolybdate 0.01 ; zinc carbonate 0.5; sucrose 296.2 . Sodium selenite $(10 \mathrm{mg} \mathrm{Se} / \mathrm{g}$ sodium selenite mixture) was added separately to make the diets; for Se $0.15 \mathrm{ppm}, 0.03$; Se 0.85 ppm, 0.2; Se $1.7 \mathrm{ppm}, 0.4$; Se $3.4 \mathrm{ppm}, 0.8$.

I The vitamin mix was free of $\alpha$-tocopherol and vitamin $A$ and was composed of $(\mathrm{g} / \mathrm{kg})$ : vitamin $\mathrm{D}_{3}(10000 \mu \mathrm{g}) 0.9$; vitamin $\mathrm{K}_{1}$ premix $(10 \mathrm{mg} / \mathrm{g})$ 110.0; biotin 0.03; folic acid 0.3; niacin 13.5; pantothenate (Ca) 1.5; riboflavin 2.3; thiamin $\mathrm{HCl} 3.0$; pyridoxine $\mathrm{HCl} 0.9$; vitamin $\mathrm{B}_{12}(0.1 \%) 1.5$; sucrose 866.1 ; vitamin $\mathrm{A}$ palmitate $(275 \mu \mathrm{g})$ was added separately to make the diets; for all diets 4.5 ; $\alpha$-tocopheryl acetate $(454 \mathrm{mg})$ was added separately to make the diets; for all diets, 0.1 . 
Food consumption was measured daily by weighing uneaten portions. Hamsters were weighed three times per week for the initial 2 weeks of feeding and thereafter, body weight was recorded on a weekly basis. All experiments were conducted in accordance with the institutional guidelines for animal care, and all experimental procedures were approved by the Health Canada Animal Care Committee and the research was conducted according to the Canadian Council on Animal Care guidelines ${ }^{(32)}$.

\section{Sample collection}

At the end of the feeding period, hamsters were fasted overnight and killed in a treatment-blocked randomised order within $2 \mathrm{~d}$. Under isoflurane anaesthesia, blood was drawn by cardiac puncture and collected in EDTA tubes for subsequent plasma isolation. After surgical exposure of the liver, bile was aspirated from the gallbladder by tuberculin syringe, transferred to sample tubes, mixed by gentle inversion and stored at $-80^{\circ} \mathrm{C}$. Immediately after removal, the liver pieces were frozen in liquid $\mathrm{N}_{2}$. The intestine was dissected out, rinsed with filtered phosphate-buffered saline solution before separating into sections and freezing in liquid $\mathrm{N}_{2}$. Both liver and jejunum were stored at $-80^{\circ} \mathrm{C}$ until further use. During dietary treatment, and near the end of the feeding phase, faeces was collected on three consecutive days and stored at $-20^{\circ} \mathrm{C}$ until further use.

\section{Plasma lipid analysis}

The measurement of plasma lipids included total cholesterol (TC), LDL-cholesterol (LDL-C), HDL-cholesterol (HDL-C), and TAG and was carried out according to the manufacturer's instructions using commercially available kit assays. Randox enzymatic reagent kits (Randox Laboratories Limited, Antrim, UK) were used for the measurement of plasma TC, HDL-C and TAG. Plasma LDL-C was assessed using Wako L-Type LDL kit assay (Wako Pure Chemical Industries Limited, Osaka, Japan).

\section{Liver lipid analysis}

Hepatic TC, free cholesterol (FC), cholesteryl ester and TAG were determined from lipid extracts via a method developed by Carr et al. ${ }^{(33)}$ using commercially available enzymatic assay kits. Hepatic TC was determined using cholesterol E reagent (Wako Pure Chemical Industries Limited). Hepatic FC was measured using free cholesterol C enzymatic colorimetric method (Wako Pure Chemical Industries Limited). The hepatic cholesteryl ester concentration was calculated by the difference between liver TC and FC. Hepatic TAG concentrations were determined using Wako L-Type TAG $\mathrm{H}$ Reagents 1 and 2 (Wako Pure Chemical Industries Limited). Briefly, tissue lipids were extracted from approximately $200 \mathrm{mg}$ of liver tissue (wet weight) using $30 \mathrm{ml}$ chloroformmethanol (2:1) according to the method of Folch et al. ${ }^{(34)}$. For the enzymatic determination of hepatic tissue lipids, all assays were performed using $50 \mu \mathrm{l}$ aliquots of sample and standard using ninety-six-well microtitre plates. Separate microtitre plates were used for hepatic TC, FC and TAG determination. For the standard solution preparations, soyabean oil was used as the primary TAG standard, and cholesterol was used as the standard for both TC and FC determinations. Both soyabean oil and cholesterol were purchased from Sigma Chemical Company (St Louis, MO, USA). For all lipid assessments, assays were carried out at room temperature $\left(25^{\circ} \mathrm{C}\right)$ and were read using a multifilter microtitre plate reader (Titertek Multiskan Plus MKII; ICN Biochemicals, Cleveland, OH, USA).

\section{Liver selenium analysis}

For liver Se analysis, hepatic tissue was digested with nitric acid and the Se content was measured using flame atomic absorption spectrophotometry (Hitachi, Polarized Zeeman AAS, Z-8200 Mississauga, Canada) ${ }^{(10)}$

\section{Liver oxysterol analysis}

Oxysterol determination was performed by GC/MS as described previously ${ }^{(35)}$. Briefly, 19-hydroxycholesterol was added to the samples as an internal standard before lipid extraction. Artifactual oxidation of cholesterol was minimised by the incorporation of L-ascorbic acid and sodium acetate to scavenge oxygen and acidic species, respectively. The lipid extract was saponified and unsaponified lipids were extracted with diethyl ether and NEFA were removed using $\mathrm{KOH}$. Bulk cholesterol was removed by solid-phase extraction and oxysterols were eluted with 2-propanol in hexane. Samples were evaporated at room temperature under $\mathrm{N}_{2}$ and converted to trimethylsilyl ethers for GC/MS analysis (Agilent 6890 GC System with 5973 Mass Selective Detector, Agilent Technologies, Wilmington, DE, USA) using a J\&W DB-1 capillary column with flow rate of He carrier gas of $1.0 \mathrm{ml} / \mathrm{min}$. The injector was operated in splitless mode and with an initial temperature of $290^{\circ} \mathrm{C}$. After injection, oven temperature began at $80^{\circ} \mathrm{C}$, and was then programmed at a rate of $30^{\circ} \mathrm{C} / \mathrm{min}$ to a final temperature of $215^{\circ} \mathrm{C}$, held for $2 \mathrm{~min}$, followed by a rate of $2^{\circ} \mathrm{C} / \mathrm{min}$ to a final temperature of $280^{\circ} \mathrm{C}$, held for $10 \mathrm{~min}$. A volume of $1 \mu \mathrm{l}$ per sample was injected. Oxysterol analysis was carried out using selected ion monitoring. The multiple ion detector was focused on $\mathrm{m} / \mathrm{z}$ 145,353 and 366 for 19-hydroxycholesterol; $\mathrm{m} / z 367$ and 472 for 7-ketocholesterol; 145, 413 and 456 for 24(S)-OHC; 131, 327 and 456 for 25-OHC; $m / z$ 129, 417 and 456 for 27-OHC.

\section{RNA isolation and real-time quantitative reverse transcription-PCR}

Total RNA was extracted from frozen hamster liver tissue and jejunal samples using two passes of Trizol reagent (Invitrogen Life Technologies, Burlington, ON, Canada) for each sample. The isolated RNA was purified and DNase I treated on RNeasy mini columns (Qiagen, Mississauga, ON, Canada) using the manufacturer's recommended conditions. Purified RNA was quantified using RiboGreen RNA Quantification 
Reagent and Kit (Molecular Probes, Eugene, OR, USA), and subsequent complementary DNA synthesis was performed with Retroscript Kit (Ambion, Streetsville, ON, Canada) in accordance with the manufacturer's instructions. Real-time quantitative PCR was performed using the Mx4000 Multiplex Quantitative PCR System and Brilliant SYBR green quantitative PCR Core Reagent Kit (Stratagene, La Jolla, CA, USA). Realtime quantitative PCR was carried out for $A b c g 5, A b c g 8$, Cyp7a1, Hmgcr, Ldlr, Npc1l1 and glyceraldehyde 3-phosphate dehydrogenase $(G a p d h)$ genes using primers obtained from the literature ${ }^{(36,37)}$ or primers newly designed with PrimerQuest software (White Head Institute for Biomedical Research, Cambridge, MA, USA). To verify that the primers (Table 2) were specific for each gene of interest (GOI), sequences were analysed using the Basic Local Alignment and Search Tool on the National Center for Biotechnology Information website $^{(38)}$. In addition, the specificity of the PCR was confirmed by dissociation curve analysis of the products and by size verification of the PCR products on agarose gel. A nontemplate reaction and a no-RT reaction were included as negative controls for each experiment. Gapdh expression was not affected by Se treatment in this study and was therefore considered a valid housekeeping gene (data not shown). Standard curves for each GOI, as well as for Gapdh, were used to calculate the relative levels of mRNA for each gene. The relative amounts of each GOI were normalised to Gapdh expression levels in the liver or jejunum as an endogenous internal standard. Normalised values (GOI/Gapdh) were then calibrated to the hamsters fed the control diet (set as 1.0).

\section{Quantification of biliary and faecal bile acids and cholesterol}

The analysis of biliary total bile acids was performed using a combination of two previously published methods as described by Chijiiwa \& Nakayama ${ }^{(39)}$ and Batta et al. ${ }^{(40)}$.
Briefly, $5 \mu$ l bile were added to a $5 \mathrm{ml}$ volumetric flask containing $2 \mathrm{ml}$ ethanol and heated until boiling point in a water bath. After cooling to room temperature, ethanol was added to make $5 \mathrm{ml}$ volume and centrifuged to separate precipitated protein. To $2 \mathrm{ml}$ supernatant were added internal standards (nor-cholic acid, $10 \mu \mathrm{g}$ in $100 \mu \mathrm{l}$ ethanol and $5 \alpha$-cholestane, $10 \mu \mathrm{g}$ in $100 \mu \mathrm{l}$ ethanol), $1 \cdot 86 \%$ EDTA ( $1 \mathrm{ml}), 0 \cdot 87 \%$ mercaptoethanol $(1 \mathrm{ml}), 0.1 \mathrm{mg}$ cholyglycine hydrolase and $0.1 \mathrm{mg}$ $\beta$-glucuronidase (suspended together in $2 \mathrm{ml}$ acetate buffer, $\mathrm{pH}$ 5.6); and the resulting suspension was incubated in a dry bath at $37^{\circ} \mathrm{C}$ for $18 \mathrm{~h}$. After hydrolysis, the contents were acidified to $\mathrm{pH} 1.0$ using $\mathrm{HCl}$ followed by extraction with ethyl acetate $(3 \times 5 \mathrm{ml})$. Pooled ethyl acetate was evaporated to dryness and the residue was subjected to $n$-butyl ester formation with the addition of $200 \mu \mathrm{l} n$-butanol and $20 \mu \mathrm{l} \mathrm{HCl}$, and the contents were heated at $60^{\circ} \mathrm{C}$ for $4 \mathrm{~h}$ and the solvents were evaporated under $\mathrm{N}_{2}$. The esterified bile acids and cholesterol were reacted with $100 \mu$ l of Sil-prep (hexamethyldisilazane-trimethylchlorosilane-pyridine (3:1:9); Alltech Associates, Deerfield, IL, USA) for $30 \mathrm{~min}$ at $55^{\circ} \mathrm{C}$ and the solvents were evaporated under $\mathrm{N}_{2}$. The trimethylsilyl ether derivatives formed were taken in $100 \mu$ l of hexane, transferred to a sample vial and capped. Then, $1 \mu$ was injected into the GLC column for analysis in the 20:1 split mode.

The analysis of faecal bile acids was performed as described by Batta et al. ${ }^{(41)}$. To $10-15 \mathrm{mg}$ freeze-dried stool (weighed exactly) were added internal standards (nor-cholic acid, $20 \mu \mathrm{g}$ in $100 \mu \mathrm{l} n$-butanol) and ( $5 \alpha$-cholestane, $20 \mu \mathrm{g}$ in $100 \mu \mathrm{l} n$-butanol), followed by $20 \mu \mathrm{l}$ concentrated $\mathrm{HCl}$. The contents were subjected to $n$-butyl ester formation by heating contents at $60^{\circ} \mathrm{C}$ for $4 \mathrm{~h}$ and evaporation under $\mathrm{N}_{2}$. Dried residue was reacted with $100 \mu$ l of Sil-prep for $30 \mathrm{~min}$ at $55^{\circ} \mathrm{C}$, and the solvents were evaporated under $\mathrm{N}_{2}$. The trimethylsilyl ether derivatives formed were taken in $200 \mu \mathrm{l}$ of hexane, and centrifuged to separate the stool debris. The clear supernatant $(100 \mu \mathrm{l})$ was transferred to a sample vial

Table 2. Oligonucleotide primers used for real-time PCR

\begin{tabular}{llll}
\hline Gene & Gene accession no. or reference & Primers & Primer sequence $5^{\prime}-3^{\prime}$ \\
\hline Abcg5 & Mouse NM_031884.1 & Sense & AGG ACT GGA CTG CAT GAC TGC AAA \\
& Rat NM_053754.2 & Antisense & CAG AAC ACC AAC TCT CCG TAA GTC AG \\
Abcg8 & Mouse NM_026180 & Sense & ACC TAC AGT GGT CAG TCC AAC ACT \\
& Rat AF351785.2 & Antisense & TTT CAT CTT GCC ACC GTG GTC TCT \\
Cyp7a1 & L04690.1 & Sense & GCA TTT GGA CAC AGA AGC ATT GAC CC \\
& & Antisense & GTG ACC CAG GCA TCA CTC TTT GAT \\
Gapdh & MAU10983 & Sense & TCA AGA AGG TGG TGA AGC AGG C \\
& AF312092 & Antisense & GCA TCA AAG GTG GAA GAG TGG G \\
& Yu et al. ${ }^{(36)}$ & & \\
Hmgcr & X00494.1 & Sense & AGC AAG TGG TCC CAC GAA TGA AGA \\
& Shimomura et al. ${ }^{(37)}$ & Antisense & GCT CCT TGA ACA CCT AGC ATC TGC \\
Ldlr & Shimomura et al. ${ }^{(37)}$ & Sense & TTG GAC AAC AAT GGT GGC TGT TCC \\
& & Antisense & TTG CAG ACC CTG GTG TGA GG \\
Npc1l1 & NM_031884.1 & Sense & TGC TGC CGC CTT TAT ATC TTT GGC \\
& & Antisense & TTG TGA AAC TGT TCT GCT GTG GGC \\
\hline
\end{tabular}

Abcg5, ATP binding cassette transporter $95 ;$ Abcg8, ATP binding cassette transporter g8; Cyp7a1, 7-hydroxylase; Gapdh, glyceraldehyde-3-phosphate-dehydrogenase; Hmgcr, 3-hydroxy-3-methylglutaryl-CoA reductase; Ldlr, LDL receptor; Npc1/1, Niemann-pick C1-like 1 protein. 
and capped. And then, $1 \mu \mathrm{l}$ was injected into the GLC column for analysis in the 20:1 split mode.

Internal standards - nor-cholic acid (23-NOR-5 $\beta$-cholanic acid- $3 \alpha, 7 \alpha, 12 \alpha$-triol) and cholestane ( $5 \alpha$-cholestane), and standards - chenodeoxycholic acid ( $3 \alpha, 7 \alpha$-dihydroxy- $5 \beta$-cholanoic acid), cholic acid $(3 \alpha, 7 \alpha, 12 \alpha$-trihydroxy- $5 \beta$-cholanoic acid), lithocholic acid ( $3 \alpha$-hydroxy- $5 \beta$-cholanoic acid), deoxycholic acid ( $3 \alpha, 12 \alpha$-dihydroxy- $5 \beta$-cholanoic acid), ursocholanic acid ( $5 \beta$-cholanic), ursodeoxycholic acid $(3 \alpha, 7 \beta$-dihydroxy$5 \beta$-cholanoic acid), hyodeoxycholic acid ( $3 \alpha, 6 \alpha$-dihydroxy- $5 \beta$ cholanoic acid) and cholesterol (5-cholesten-3 $\beta$-ol) were purchased from Steraloids, Inc. (Newport, RI, USA). All standards contained the internal standards nor-cholic acid and $5 \alpha$-cholestane. Standard concentrations ranged between 0.02 and $0.2 \mu \mathrm{g}$ bile acid per $1 \mu$ l hexane injected and were subjected to $n$-butyl ester formation and trimethylsilylation as delineated previously.

Identification and quantification of bile acids were achieved using a Hewlett-Packard model 6890 gas chromatograph equipped with a flame ionisation detector and injector with a split/splitless device for capillary columns. The chromatographic column used was a J\&W 122-1031 capillary column (30 $\mathrm{m} \times 0.250 \mathrm{~mm}$ internal diameter). Helium was used as the carrier gas. The gas chromatograph operating conditions were as follows: injector and detector temperatures were 260 and $290^{\circ} \mathrm{C}$, respectively. After injection, oven temperature was kept at $150^{\circ} \mathrm{C}$ for $1 \mathrm{~min}$, programmed at a rate of $7^{\circ} \mathrm{C} / \mathrm{min}$ to reach a final temperature of $272^{\circ} \mathrm{C}$.

\section{Hepatic protein determination}

Protein concentrations were determined using the Bradford reagent (Sigma). Bovine serum albumin stock in saline was used as the standard ${ }^{(10)}$.

\section{Statistical analysis}

Statistical analyses were performed using the mixed model procedure (MIXED) for all analyses using SAS version 9.1, with a significance level less than or equal to 0.05 (SAS Institute, Cary, NC, USA) ${ }^{(42)}$. Blocking was an integral part of the experimental design owing to kill order and assaying, which occurred in distinct blocks over time, and to the use of microtitre plates for hepatic and plasma lipid analysis and for mRNA analysis. Blocking can be viewed as another independent variable introduced only for the purpose of controlling error variation. Normality was measured based on residuals using the Shapiro-Wilk test. The statistical significance of the differences between least square means was determined using the protected least squares means test. Correlations between tissue Se and biochemical measurements were examined by using Spearman's correlation coefficient by rank.

\section{Results}

Selenite supplementation increased hepatic selenium concentrations and did not affect biliary or faecal bile acid and cholesterol concentrations, average daily intake, final body weight or liver weight of hamsters

Each increment of dietary selenite resulted in significantly higher liver Se concentrations ( $\mu \mathrm{mol} / \mathrm{g}$ wet weight) of 0.51 (SEM 0.03); 0.62 (SEM 0.03); 0.81 (SEM 0.03); 1.03 (SEM 0.03), with the Se $0.15 \mathrm{ppm}$, Se $0.85 \mathrm{ppm}$, Se $1.7 \mathrm{ppm}$ and Se $3.4 \mathrm{ppm}$ diets, respectively. No effect of selenite treatment was noted on biliary or faecal TC or bile acid concentrations (data not shown). Hamsters consuming the Se 0.15 ppm, Se $0.85 \mathrm{ppm}$, Se $1.7 \mathrm{ppm}$ and Se $3.4 \mathrm{ppm}$ diets showed biliary TC concentrations ( $\mu \mathrm{mol} / \mathrm{ml}$ bile) of 13 (SEM 1.5); 11 (sEM 1.3); 12 (SEM 1.4); 10 (SEM 1.4) and faecal TC concentrations ( $\mu \mathrm{mol} / \mathrm{g}$ faeces) of $5 \cdot 8$ (SEM 1.1), $7 \cdot 0$ (SEM 2.6), 8.3 (SEM 2.5) and $9 \cdot 2$ (SEM 1.9), respectively.

No effect of selenite treatment was observed on average daily intake, final body weight or liver weight. Final body weights (g) for hamsters consuming the diets were 116.1 (SEM 3.03); 109.4 (SEM 3.03); 111.3 (SEM 3.03); 108.8 (SEM 3.03 ) for the Se $0.15 \mathrm{ppm}$, Se $0.85 \mathrm{ppm}$, Se $1.7 \mathrm{ppm}$ and Se $3.4 \mathrm{ppm}$ diets, respectively. Hamsters consuming the Se $0.15 \mathrm{ppm}$, Se $0.85 \mathrm{ppm}$, Se $1.7 \mathrm{ppm}$ and Se $3.4 \mathrm{ppm}$ diets consumed on average on a daily basis (g) 7.2 (SEM 0.18), $6 \cdot 6$ (SEM $0 \cdot 18), 6 \cdot 9(\operatorname{SEM} 0 \cdot 18)$ and $7 \cdot 2(\operatorname{SEM} 0 \cdot 18)$, respectively.

\section{Selenite supplementation decreased plasma cholesterol concentrations}

Hamsters consuming the Se $3.4 \mathrm{ppm}$ and Se $0.85 \mathrm{ppm}$ diets as compared to the Se $0 \cdot 15 \mathrm{ppm}$ diet showed lower plasma TC

Table 3. Effect of dietary selenite supplementation on plasma total cholesterol (TC), HDL-cholesterol (HDL-C), LDL-cholesterol (LDL-C), TAG and LDL-C:HDL-C ratio in adult male Syrian hamsters fed high-cholesterol and high-saturated fat diets for 4 weeks

(Mean values with their standard errors, $n 10$ )

\begin{tabular}{|c|c|c|c|c|c|c|c|c|}
\hline & \multicolumn{2}{|c|}{ Se $(0.15 p p m)$} & \multicolumn{2}{|c|}{$\mathrm{Se}(0.85 \mathrm{ppm})$} & \multicolumn{2}{|c|}{ Se (1.7ppm) } & \multicolumn{2}{|c|}{ Se (3.4 ppm) } \\
\hline & Mean & SEM & Mean & SEM & Mean & SEM & Mean & SEM \\
\hline $\mathrm{TC}(\mathrm{mmol} / \mathrm{l})$ & $4 \cdot 77^{\mathrm{a}}$ & 0.11 & $4 \cdot 22^{b}$ & 0.24 & $4 \cdot 54^{a, b}$ & 0.21 & $4 \cdot 29^{b}$ & 0.15 \\
\hline HDL-C (mmol/l) & $1.76^{a}$ & 0.14 & $1 \cdot 31^{\mathrm{b}}$ & 0.14 & $1 \cdot 69^{\mathrm{a}}$ & 0.14 & $1.65^{\mathrm{a}}$ & 0.14 \\
\hline LDL-C $(\mathrm{mmol} / \mathrm{l})^{*}$ & $1 \cdot 39^{a}$ & 0.04 & $1 \cdot 36^{\mathrm{a}}$ & 0.04 & $1 \cdot 29^{b}$ & 0.03 & $1 \cdot 25^{b}$ & 0.04 \\
\hline TAG $(\mathrm{mmol} / \mathrm{l})$ & $2 \cdot 46^{\mathrm{a}}$ & 0.31 & $2.99^{a, b}$ & 0.37 & $3.58^{\mathrm{b}}$ & 0.32 & $2 \cdot 28^{a}$ & 0.31 \\
\hline LDL-C:HDL-C & $0.75^{a}$ & 0.08 & $1 \cdot 10^{b}$ & 0.08 & $0.82^{a}$ & 0.08 & $0.72^{a}$ & 0.08 \\
\hline
\end{tabular}

ppm, Parts per million.

${ }_{a, b, c}$ Mean values within a row with unlike superscript letters were significantly different $(P \leq 0.05$; Mixed model).

* Plate significant in statistical model. 
Table 4. Effect of dietary selenite supplementation on liver total cholesterol (TC), cholesteryl ester (CE), free cholesterol (FC) and TAG in adult male Syrian hamsters fed high-cholesterol and highsaturated fat diets for 4 weeks

(Mean values with their standard errors, $n$ 10)

\begin{tabular}{|c|c|c|c|c|c|c|c|c|}
\hline & \multicolumn{2}{|c|}{ Se $(0.15 \mathrm{ppm})$} & \multicolumn{2}{|c|}{ Se $(0.85 \mathrm{ppm})$} & \multicolumn{2}{|c|}{ Se $(1.7 p p m)$} & \multicolumn{2}{|c|}{$\mathrm{Se}(3.4 \mathrm{ppm})$} \\
\hline & Mean & SEM & Mean & SEM & Mean & SEM & Mean & SEM \\
\hline $\mathrm{TC}(\mu \mathrm{mol} / \mathrm{g}$ wet $\mathrm{wt})$ & 101 & 6 & 98 & 6 & 96 & 6 & 109 & 7 \\
\hline $\mathrm{CE}(\mu \mathrm{mol} / \mathrm{g}$ wet $\mathrm{wt})$ & 98 & 6 & 88 & 5 & 88 & 5 & 98 & 5 \\
\hline FC ( $\mu \mathrm{mol} / \mathrm{g}$ wet $w t)$ & 10 & 1 & 11 & 1 & 9 & 1 & 9 & 1 \\
\hline TAG $(\mu \mathrm{mol} / \mathrm{g} \text { wet } \mathrm{wt})^{*}$ & $160^{a}$ & 23 & $171^{\mathrm{a}}$ & 29 & $228^{\mathrm{b}}$ & 24 & $262^{b}$ & 23 \\
\hline
\end{tabular}

ppm, Parts per million; wt, weight.

${ }_{a, b, c}$ Mean values within a row with unlike superscript letters were significantly different $(P \leq 0.05$; Mixed model).

* Plate significant in statistical model.

concentrations (Table 3). The effect of dietary selenite on plasma LDL-C was significant, with hamsters consuming the Se $3.4 \mathrm{ppm}$ and Se $1.7 \mathrm{ppm}$ diets showing lower plasma concentrations of LDL-C in comparison to hamsters consuming the Se $0.15 \mathrm{ppm}$ control diet. Decreased plasma HDL-C concentrations were noted in hamsters consuming the Se $0.85 \mathrm{ppm}$ diet as compared to hamsters consuming the Se $0.15 \mathrm{ppm}$ diet. Hamsters receiving the Se $0.85 \mathrm{ppm}$ diet showed significantly higher LDL-C:HDL-C ratios as compared to hamsters consuming the Se $0 \cdot 15$ pm diet. Increased plasma TAG concentrations were noted in hamsters consuming the Se $1.7 \mathrm{ppm}$ diet versus hamsters fed the Se $0 \cdot 15 \mathrm{ppm}$ diet.

\section{Selenite supplementation increased liver TAC concentrations}

Hamsters consuming the Se $3.4 \mathrm{ppm}$ and Se $1.7 \mathrm{ppm}$ diets showed significantly greater concentration of hepatic TAG as compared to hamsters consuming the Se $0 \cdot 15 \mathrm{ppm}$ diet (Table 4).

\section{Selenite supplementation up-regulated hepatic ATP binding cassette transporter g8 and $L D L$ receptor mRNA expression}

Hamsters consuming the Se $3.4 \mathrm{ppm}$, Se $1.7 \mathrm{ppm}$ and Se $0.85 \mathrm{ppm}$ diets showed significantly greater levels of $A b c g 8$ mRNA in their livers as compared to hamsters consuming the control Se $0 \cdot 15$ ppm diet (Fig. 1). Similarly, hamsters consuming the Se $3.4 \mathrm{ppm}$ and Se $1.7 \mathrm{ppm}$ diets both had higher hepatic levels of $L d l r$ mRNA in comparison to hamsters fed the control Se $0 \cdot 15 \mathrm{ppm}$ diet.

\section{Selenite supplementation up-regulated jejunal Ldl receptor and down-regulated Niemann-pick C1-like 1 protein mRNA expression}

Hamsters consuming the Se $3.4 \mathrm{ppm}$ and Se $1.7 \mathrm{ppm}$ diets showed higher jejunal levels of $L d l r$ mRNA as compared to hamsters fed the control Se $0 \cdot 15 \mathrm{ppm}$ diet (Fig. 2). Hamsters consuming the Se $3.4 \mathrm{ppm}$ and Se $1.7 \mathrm{ppm}$ diets had lower jejunal levels of $N p c 1 l 1$ mRNA expression as compared to hamsters fed the control Se $0 \cdot 15 \mathrm{ppm}$ diet. The supplementation of
Se showed a tendency to increase $A b c g 8$ mRNA expression levels in the jejunum of hamsters consuming the Se diets $(P=0 \cdot 08)$.

\section{Selenite supplementation increased hepatic 27-hydroxycholesterol concentrations}

Hamsters fed the Se $3.4 \mathrm{ppm}$ and Se $1.7 \mathrm{ppm}$ diets showed increased hepatic concentrations of $27-\mathrm{OHC}$ as compared to hamsters fed the control Se $0 \cdot 15 \mathrm{ppm}$ diet (Fig. 3). Hepatic 27-OHC concentrations showed a tendency to correlate with hepatic mRNA abundance of $\operatorname{Abcg} 8\left(r^{2} 0 \cdot 3, P=0 \cdot 10\right)$.

\section{Discussion}

The major aim of the present study was to elucidate the mechanisms of cholesterol-lowering action of Se supplementation by examining the dose-response effect of supplemental selenite on the mRNA expression of Abcg5, Abcg8 and Npc1l1 transporters in relation to tissue cholesterol concentrations ${ }^{(1-17)}$.

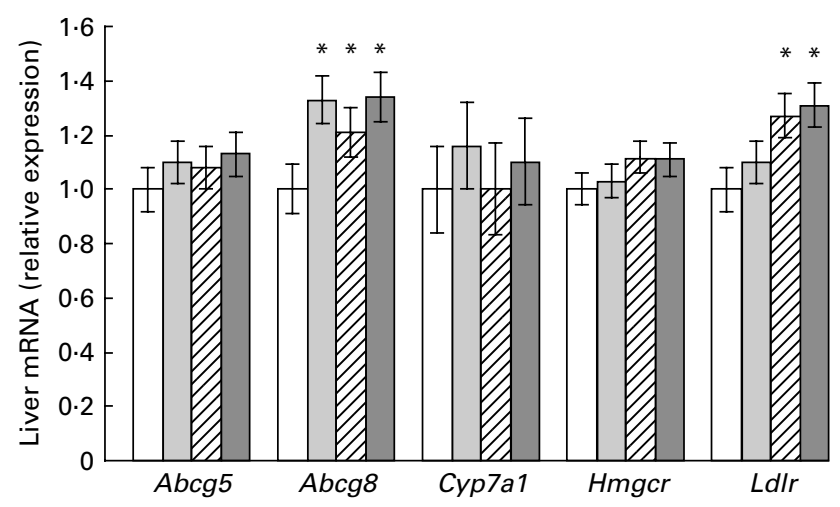

Fig. 1. Effect of selenite supplementation on hepatic ATP-binding cassette transporter g5 (Abcg5), ATP-binding cassette transporter $g 8$ (Abcg8), 7-hydroxylase (Cyp7a1), 3-hydroxy-3-methylglutaryl-coenzyme A reductase (Hmgcr) and LDL receptor (Ldlr) mRNA expression levels in adult Syrian hamsters fed high-cholesterol and high-saturated fat (HCHS) diets for 4 weeks. Data are relative amounts of genes of interest normalised to glyceraldehyde 3-phosphate dehydrogenase expression levels as an endogenous internal standard. Normalised values are calibrated to hamsters fed control (selenium (Se) 0.15 parts per million (ppm)) diet, with control expression set at 1 . $\square$, Se $0.15 \mathrm{ppm}$; $\square$, Se $0.85 \mathrm{ppm}$; $\square$, Se $1.7 \mathrm{ppm}$; $\square$, Se $3.4 \mathrm{ppm}$. Values are means, with their standard errors represented by vertical bars $(n$ 10). * Mean value was significantly different from that for the control Se 0.15 $\operatorname{diet}(P \leq 0.05$; Mixed model). 


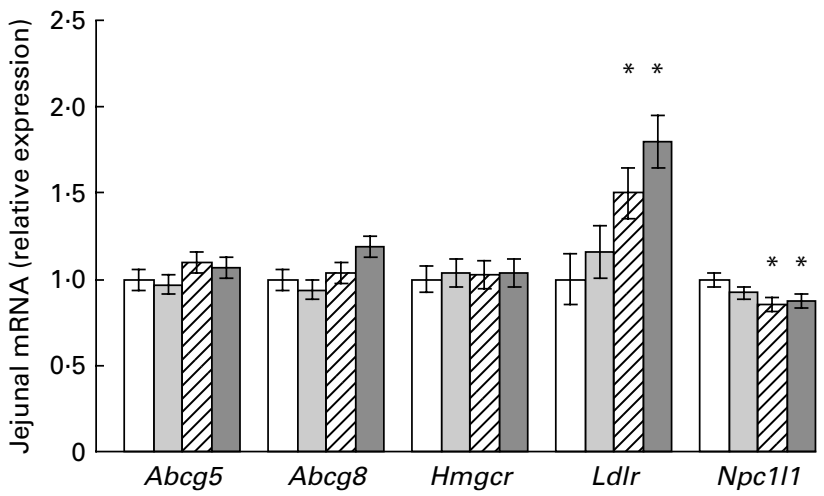

Fig. 2. Effect of selenite supplementation on jejunal ATP-binding cassette transporter $g 5$ (Abcg5), ATP-binding cassette transporter g8 (Abcg8), 3-hydroxy-3-methylglutaryl-coenzyme A reductase (Hmgcr), LDL receptor (Ldlr) and Niemann-pick C1-like 1 protein (Npc1/1) mRNA expression levels in adult Syrian hamsters fed high-cholesterol and high-saturated fat diets for 4 weeks. Data are relative amounts of genes of interest normalised to glyceraldehyde 3-phosphate dehydrogenase expression levels as an endogenous internal standard. Normalised values are calibrated to hamsters fed control selenium (Se) 0.15 parts per million (ppm) diet, with control expression set at $1 . \square$, Se $0.15 \mathrm{ppm}$; $\square$, Se $0.85 \mathrm{ppm}$; $\square$, Se $1.7 \mathrm{ppm}$; $\square$, Se $3.4 \mathrm{ppm}$. Values are means, with their standard errors represented by vertical bars ( $n$ 10). * Mean value was significantly different from that for the control Se $0.15 \mathrm{ppm}$ diet $(P \leq 0.05$; Mixed model).

A notable finding was the association between the three doses of Se $(0.85,1.7$ and $3.4 \mathrm{ppm})$ and the increased expression of hepatic Abcg8 despite no change in hepatic Abcg 5 mRNA abundance (Fig. 1). Likewise, selenite supplementation was associated with a tendency to increased $\operatorname{Abcg} 8$ with no effect on $A b c g 5$ mRNA expression levels in the jejunum (Fig. 2). The combination of unchanged hepatic $A b c g 5$ mRNA expression and up-regulation of hepatic $A b c g 8$ mRNA abundance is in concordance with the lack of effect of selenite supplementation on biliary cholesterol content, as both $\mathrm{Abcg} 5$ and $A b c g 8$ are required for biliary cholesterol secretion ${ }^{(21)}$. The present study thus indicates that biliary cholesterol secretion through up-regulation of the heterodimer of $A b c g 5$ and $A b c g 8$ transporters is not a primary cholesterol-lowering mechanism associated with selenite supplementation. As selenite supplementation was also not associated with altered faecal TC concentrations, it appears that increased faecal excretion of cholesterol mediated via the heterodimer of $A b c g 5$ and $A b c g 8$ transporters is not involved as a primary cholesterol-lowering mechanism of selenite supplementation. Selenite supplementation was not associated with altered biliary or faecal bile acid concentrations (data not shown) or hepatic Cyp7a1 mRNA expression levels (Fig. 1), which is compatible with the unchanged liver cholesterol content ${ }^{(43)}$. The present findings are in contrast to the observations of Iizuka et $a l .{ }^{(7)}$, who showed significant lowering of hepatic cholesterol concentrations in Se-supplemented rats fed a $1 \%$ cholesterol diet and $0.5 \%$ cholic acid for 10 weeks. The addition of dietary cholic acid may account for the aforementioned study differences since cholic acid can stimulate the $A b c g 5 / A b c g 8$ pathway to increase biliary cholesterol secretion $^{(44)}$.
The observation of unchanged tissue $A b c g 5$ and increased Abcg 8 mRNA expression with selenite supplementation contrasts with the coordinated regulation of the two transporters shown with activation of the liver $\mathrm{X}$ receptor ${ }^{(45)}$, which has been suggested to be the primary regulator of $A b c g 5$ and $A b c g 8^{(46)}$ and that acts as a cellular cholesterol sensor. To date, however, a liver $\mathrm{X}$ responsive element has not yet been identified in the $5^{\prime}$-flanking region of the Abcg 5 and $A b c g 8$ genes, and the mechanism of regulation of the genes is currently unknown. The extent to which Se-induced changes in tissue $A b c g 8$ contributed to the observed decreased plasma lipid concentrations (Table 3) is not clear. A very recent study, investigating the effect of low levels of supplemental selenate in growing rats, observed a tendency for increased plasma TC concentrations and decreased Abcg 8 mRNA expression in the livers of supplemented rats as compared to Se-sufficient rats ${ }^{(47)}$. Interestingly, polymorphisms in $\operatorname{Abcg} 8$ but not $A b c g 5$ genes have been related to higher serum TC and LDL-C concentrations in humans ${ }^{(48)}$. In the present study, increases in hepatic $A b c g 8$ were associated with either lowered plasma TC of hamsters receiving $0.85 \mathrm{ppm}$ Se or lowered LDL-C concentrations in hamsters fed $1.7 \mathrm{ppm}$ Se (Table 3). In hamsters receiving the highest Se dose of $3.4 \mathrm{ppm}$, increased tissue $\mathrm{Abcg} 8 \mathrm{mRNA}$ expression was associated with decreased plasma concentrations of both TC and LDL-C (Table 3). Although hepatic concentrations of 27-OHC were increased by selenite supplementation at the two highest doses (1.7 and $3.4 \mathrm{ppm}$; Fig. 3), only a weak tendency to correlate was noted between $A b c g 8$ mRNA expression and hepatic levels of 27-OHC $\left(r^{2} 0 \cdot 3 ; P=0 \cdot 10\right)$ and no correlation was noted between hepatic 27-OHC content and hepatic expression of $A b c g 5$. These latter results contrast with the findings of Chen et al. ${ }^{(27)}$ that suggest a regulatory role for hepatic 24(S)-OHC, 25-OHC and 27-OHC on hepatic Abcg5 and $A b c g 8$ mRNA expression in the murine model. The aforementioned differences may be related to the species-specific

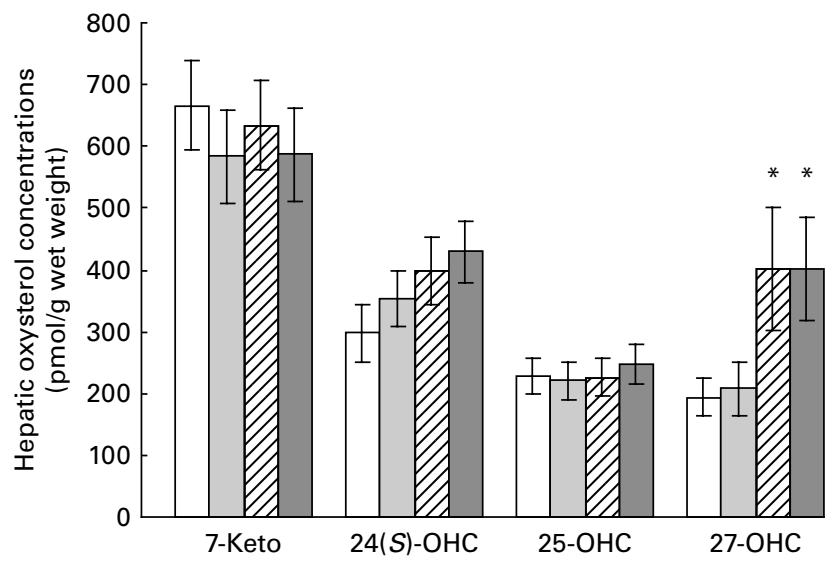

Fig. 3. Effect of selenite supplementation on hepatic oxysterol concentrations in adult male Syrian hamsters fed high-cholesterol and high-saturated fat diets for 4 weeks. $\square$, Selenium (Se) 0.15 parts per million (ppm); $\square$, Se $0.85 \mathrm{ppm}$; $\boldsymbol{\nabla}$, Se $1.7 \mathrm{ppm}$; $\square$, Se $3.4 \mathrm{ppm}$. Values are means, with their standard errors represented by vertical bars $(n 10)$. ${ }^{*}$ Mean values were significantly different from control ( $P \leq 0.05$; Mixed model). 7-Keto, 7-ketocholesterol; 24(S)-OHC, 24-hydroxycholesterol; 25-OHC, 25-hydroxycholesterol; 27-OHC, 27-hydroxycholesterol. 
responses of $A b c g 5$ and $A b c g 8$ expression to cholesterol treatment ${ }^{(49)}$. The increased hepatic $27-\mathrm{OHC}$ concentrations with selenite supplementation were probably the result of enhanced Cyp27a1 mRNA expression that we have shown previously ${ }^{(10)}$.

The possible mechanisms involved with the decrease in Npc1l1 mRNA abundance noted in the jejunum of hamsters consuming the higher Se doses ( 1.7 and $3.4 \mathrm{ppm})$ are unclear. Regulation of $N p c 111$ gene expression is largely unknown and inconsistent ${ }^{(46)}$ and similar to $A b c g 5 / g 8$, a liver $\mathrm{X}$ responsive element in the promoter of NPC1L1 has not yet been identified $^{(46)}$. Decreased jejunal expression of $N p c 111$ could be related to the decreased plasma LDL-C concentrations seen with these diets (Table 3). Ezetimibe monotherapy, which targets NPC111, lowers plasma LDL-C concentrations in humans ${ }^{(50)}$. As the levels of hepatic TC, a surrogate marker of cholesterol absorption ${ }^{(24)}$, remained unchanged with selenite supplementation (Table 4) along with no significant increases in faecal cholesterol, the possible relationship between decreased $N p c 1 l 1$ expression and lowered plasma LDL-C remains speculative. As selenite supplementation has been shown to significantly enhance fermentation in the rat colon $^{(51)}$, it is conceivable that decreased Npc1l1 mRNA expression resulted in increased faecal TC concentrations producing unmeasured cholesterol metabolites via intestinal microbial conversion.

The increases in Ldlr mRNA abundance (Figs. 1 and 2) shown in the tissues of hamsters consuming the two highest doses of Se (1.7 and $3.4 \mathrm{ppm})$ might be related to the lowered plasma LDL-C concentrations. LDL-C is cleared from the circulation mainly through uptake by the hepatic LDL receptor as most plasma LDL-C turnover is accounted for by hepatic and small-intestine uptake ${ }^{(52)}$. The findings of the present study are in agreement with Dhingra \& Bansal $^{(6)}$, who reported similar increases in hepatic Ldlr mRNA expression levels and lowered plasma LDL-C concentrations in rats fed a high cholesterol (2\%) diet receiving $1.0 \mathrm{ppm}$ selenite supplementation $^{(6)}$. The increased hepatic Ldlr mRNA together with unchanged hepatic cholesterol content suggests that nonsterol mechanisms might be involved in selenite-induced hepatic LDL-C clearance in the Syrian hamster. Although Ldlr mRNA expression is regulated by the cellular concentrations of cholesterol $^{(53)}$ and oxysterols ${ }^{(54)}$ through the sterol regulatory element-binding protein 2 transcription factor pathway, other transcription factors can intervene in this regulatory process $^{(55)}$. In support of this latter contention, a recent study showed an absence of effect of selenite supplementation on hepatic sterol regulatory element-binding protein 2 mRNA expression relative to Se-sufficient rats $^{(47)}$. The unchanged liver TC concentrations by selenite supplementation might be due to the inability of selenite to modulate hepatic Hmgcr mRNA abundance (Fig. 1). The absence of effect of selenite on Hmgcr mRNA expression agrees with similar recent findings shown in growing rats fed with a low-fat, low-cholesterol diet following sodium selenate supplementation $^{(47)}$, which suggests that intake of fat and cholesterol does not modulate the lack of impact of Se supplementation on hepatic Hmgcr mRNA expression. On the other hand, our findings differ from previous rat studies showing decreased hepatic Hmgcr mRNA expression in conjunction with high-cholesterol diets supplemented with $1.0 \mathrm{ppm}$ selenite ${ }^{(5)}$. The above contrasting results in hepatic Hmgcr mRNA expression may be due to species differences in regulation of the Hmgcr gene when faced with a cholesterol challenge $^{(43)}$.

Supplementation of selenite at the $0.85 \mathrm{ppm}$ Se dose was associated with significantly decreased plasma concentrations of HDL-C, which was not observed with the two highest doses of Se (1.7 and $3.4 \mathrm{ppm}$; Table 3 ). The latter result is in agreement with previous hamster work showing no effect on plasma HDL-C levels from high-dose Se supplementation ${ }^{(17)}$. Plasma concentrations of TAG were increased following Se intake at $1.7 \mathrm{ppm}$, which might be partly due to lower plasma lipoprotein lipase activity, which has previously been shown to be lowered by high dietary selenite $(5 \mathrm{mg} / \mathrm{kg}$ diet $)$ in tumour-bearing Wistar rats $^{(11)}$. Conversely, the highest dose of Se $(3.4 \mathrm{ppm})$ showed no effect on plasma TAG levels as compared to control, which agrees with previous work with hamsters fed comparable levels of fat and cholesterol $^{(9)}$ and in hamsters fed comparable levels of Se in conjunction with a standard rodent $\operatorname{diet}^{(17)}$. In contrast, previous studies have shown significant decreases in plasma TAG concentrations in human subjects ${ }^{(3)}$, rats ${ }^{(12)}$ and mice ${ }^{(8)}$. Discrepancy in results may be related to differences in species, dosage, duration of feeding trial or form of Se used. Higher hepatic TAG concentrations were observed with the higher doses (1.7 and 3.4 ppm; Table 4). The mechanisms underlying the effects of selenite on hepatic TAG concentrations are not clear but are consistent with the associations shown in rodent models between Se and increases in fatty acid synthase mRNA expression ${ }^{(7)}$, PPAR- $\gamma$ expression ${ }^{(8)}$ and protein tyrosine phosphatase $1 \mathrm{~B}$ activity ${ }^{(56)}$, which have also been associated with fatty liver and insulin resistance in rats fed high-fructose diets ${ }^{(57)}$. Thus, it is possible that reduced insulin sensitivity could be a long-term consequence of increased liver TAG concentrations noted in the hamsters receiving the 1.7 and $3.4 \mathrm{ppm}$ Se doses. These latter findings demonstrate the importance of examining liver lipid metabolism when assessing suitability of the plasma lipid-lowering effects of high-dose Se supplementation that is receiving increased research attention ${ }^{(58)}$. The aforementioned results also call into question the long-term intake of selenite above nutrient recommendations due to potentially harmful increases in hepatic TAG that could predispose to decreased insulin sensitivity, despite the possible benefits of lowered plasma cholesterol concentrations. Future studies would need to be performed in higher primate experimental models for closer extrapolation of the aforementioned findings to humans.

The use of a rodent species to model the human response to dietary Se intake is a limitation of the present study. Regardless, the Syrian hamster is the rodent model most similar to humans with regard to cholesterol metabolism ${ }^{(18,19)}$ and the present study is the first to explore the potential mechanisms of Se on cholesterol metabolism in the Syrian hamster as opposed to other models such as the rat. In contrast to the hamster, the rat is resistant to diet-induced hypercholesterolaemia due to 
its ability to down-regulate hepatic activity of $\mathrm{Hmgcr}$ and to stimulate Cyp7a1 gene abundance, and thus is highly efficient in the conversion of cholesterol into bile acids ${ }^{(55)}$. Another limitation concerns the dietary levels of Se ingested by the hamsters that correspond to 8-, 16- and 32-fold higher intakes than the human Se requirement, when adjusted for the average daily food intake and the final body weights of the hamsters. Although these Se doses appeared to be well-tolerated by the hamsters, such levels of Se intake are not normally seen in the human context, and so direct extrapolation to humans without additional experimentation is inappropriate. To identify the safe and efficacious levels of Se intakes, prospective epidemiological studies and randomised clinical trials are needed in different populations that take into account the ranges of intakes for the different speciated forms of Se.

In summary, this study examined the effect of supplemental selenite on hepatic and jejunal $A b c g 5, A b c g 8$ and Npc1l1 mRNA expression in the Syrian hamster in the context of its impact on cholesterol absorption and excretion, particularly in relation to plasma lipid levels. Supplemental selenite was shown to influence important genes involved in cholesterol homeostasis, Abcg8, Ldlr and Npc1l1, which provides insight into the mechanisms underlying the cholesterol-modulating effects of dietary Se in humans. The present findings indicate that the hypocholesterolaemic effects of supplemental selenite are not associated with biliary and faecal cholesterol secretion and do not appear to involve liver $\mathrm{X}$ receptor activation. Future studies are needed to explore the possibility that plasma cholesterol-lowering action of selenite supplementation is mediated via sterol-independent mechanisms.

\section{Acknowledgements}

The present study was supported by the National Sciences and Engineering Research Council of Canada through a grant to S. K. Additional funding for this study was awarded to K. A. C., S. K. and K. A. S., through the Innovative Science Competition, Office of the Chief Scientist, Health Canada. J. P., K. A. C., K. A. S. and S. K were responsible for the planning of the experiments and along with W. M. N. R. for evaluation of the results and writing of the manuscript. J. P. conducted the statistical evaluation of all data and all experimental analyses except for jejunal $N p c 1 l 1$ and tissue Abcg 5 mRNA expression analyses, which were conducted by E. S. and H. G., respectively. P. G. conducted the animal experiment and assisted with laboratory analyses along with H. R. and C. G. All authors read and approved the final manuscript. The authors declare that there are no conflicts of interest.

\section{References}

1. Kauf E, Dawczynski H, Jahreis G, et al. (1994) Sodium selenite therapy and thyroid-hormone status in cystic fibrosis and congenital hypothyroidism. Biol Trace Elem Res $\mathbf{4 0}$, $247-253$.

2. Luoma PV, Sotaniemi EA, Korpela H, et al. (1984) Serum selenium, glutathione peroxidase activity and high-density lipoprotein cholesterol - effect of selenium supplementation. Res Commun Chem Pathol Pharmacol 3, 469-472.
3. Djujic IS, Jozanov-Stankov ON, Milovac M, et al. (2000) Bioavailability and possible benefits of wheat intake naturally enriched with selenium and its products. Biol Trace Elem Res 77, 273-285.

4. Raymand MP, Stranges S, Griffin B, et al. (2011) Effect of supplementation with high-selenium yeast on plasma lipids: a randomized trial. Ann Intern Med 154, 656-665.

5. Dhingra S \& Bansal MP (2006) Modulation of hypercholesterolemia-induced alterations in apolipoprotein $\mathrm{B}$ and HMG-CoA reductase expression by selenium supplementation. Chem Biol Interact 161, 49-56.

6. Dhingra S \& Bansal MP (2006) Hypercholesterolemia and LDL-C receptor mRNA expression: modulation by selenium supplementation. BioMetals 19, 493-501.

7. Iizuka Y, Sakurai E \& Tanaka Y (2001) Effect of selenium on serum, hepatic and lipoprotein lipids concentration in rats fed a high-cholesterol diet. Yakugaku Zasshi 121, 93-96.

8. Mueller AS \& Pallauf J (2006) Compendium of the antidiabetic effects of supranutritional selenate doses in vivo and in vitro investigations with type II diabetic $\mathrm{Db} / \mathrm{Db}$ mice. J Nutr Biochem 17, 548-560.

9. Poirier J, Cockell K, Hidiroglou N, et al. (2002) The effects of vitamin $\mathrm{E}$ and selenium intake on oxidative stress and plasma lipids in hamsters fed fish oil. Lipids 37, 1125-1133.

10. Poirier J, Cockell KA, Ratnayake WMN, et al. (2010) Antioxidant supplements improve profiles of hepatic oxysterols and plasma lipids in butter-fed hamsters. Nutr Metab Insights 3, $1-14$.

11. Chidambaram N \& Baradarajan A (1995) Effect of selenium on lipids and some lipid metabolizing enzymes in DMBA induced mammary tumor rats. Cancer Biochem Biophys 15, 41-47.

12. Crespo AM, Lanca MJ, Vasconcelos S, et al. (1995) Effect of selenium supplementation on some blood biochemical parameters in male rats. Biol Trace Elem Res 47, 343-347.

13. Dhingra S \& Bansal MP (2006) Hypercholesterolemia and tissue-specific differential mRNA expression of type-1 5'iodothyronine deiodinase under different selenium status in rats. Biol Res 39, 307-319.

14. Dhingra S \& Bansal MP (2005) Hypercholesterolemia and apolipoprotein $\mathrm{B}$ expression: regulation by selenium status. Lipids Health Dis. 4, 28.

15. Kang BPS, Bansal MP \& Mehta U (1998) Selenium supplementation and diet induced hypercholesterolemia in the rat: changes in lipid levels, malonyldialdehyde production and the nitric oxide synthase activity. Gen Physiol Biophys 17, 71-78.

16. Kang BPS, Mehta U \& Bansal MP (1997) Effect of diet induced hypercholesterolemia and selenium supplementation on nitric oxide synthase activity. Arch Physiol Biochem 105, 603-607.

17. Vinson JA, Stella JM \& Flanagan TJ (1998) Selenium yeast is an effective in vitro and in vivo antioxidant and hypolipidemic agent in normal hamsters. Nutr Res 18, 735-742.

18. Dietschy JM (1984) Regulation of cholesterol metabolism in man and other species. Klin Wochenschr 62, 338-345.

19. Zhang Z, Wang H, Jiao R, et al. (2009) Choosing hamsters but not rats as a model for studying plasma cholesterollowering activity of functional foods. Mol Nutr Food Res 53, 921-930.

20. Yu L, Hammer RE, Li-Hawkins J, et al. (2002) Disruption of $A b c g 5$ and $A b c g 8$ in mice reveals their crucial role in biliary cholesterol secretion. PNAS 99, 16237-16242.

21. Duan L-P, Wang HH \& Wang DQ-H (2004) Cholesterol absorption is mainly regulated by the jejunal and ileal 
ATP-binding cassette sterol efflux transporters Abcg5 and Abcg8 in mice. J Lipid Res 45, 1312-1323.

22. Davis HR Jr, Zhu L-J, Hoos LM, et al. (2004) Nieman-Pick C1 Like 1 (NPC1L1) is the intestinal phytosterol and cholesterol transporter and a key modulator of whole-body cholesterol homeostasis. J Biol Chem 279, 33586-33592.

23. Basso R, Freeman LA, Ko C, et al. (2007) Hepatic ABCG5/G8 overexpression reduces apoB-lipoproteins and atherosclerosis when cholesterol absorption is inhibited. J Lipid Res $\mathbf{4 8}$, 114-126.

24. Salisbury BG, Davis HR, Burrier RE, et al. (1995) Hypocholesterolemic activity of a novel inhibitor of cholesterol absorption, SCH48461. Atherosclerosis 115, 45-63.

25. Jia X, Ebine N, Demonty I, et al. (2007) Hypocholesterolemic effects of plant sterol analogues are independent of ABCG5 and ABCG8 transporter expressions in hamsters. Br J Nutr 98, 550-555.

26. Zhang Z, Li D, Blanchard DE, et al. (2001) Key regulatory oxysterols in liver: analysis as $\delta 4-3$-ketone derivatives by HPLC and response to physiological perturbations. J Lipid Res 42, 649-658.

27. Chen W, Chen G, Head DL, et al. (2007) Enzymatic reduction of oxysterols impairs liver $\mathrm{X}$ receptor signalling in cultured cells and the livers of mice. Cell Metabol 5, 73-79.

28. National Research Council (1995) Nutrient requirements of the hamster. In Nutrient Requirements of Laboratory Animals, 4th rev. ed., pp. 125-139. Washington, DC: National Academy of Sciences.

29. Birt DF, Julius AD \& Runice CE (1986) Tolerance of low and high dietary selenium throughout the life span of Syrian hamsters. Ann Nutr Metab 30, 233-240.

30. Beems RB \& van Beek L (1985) Short-term (6-week) oral toxicity study of selenium in Syrian hamsters. Food Chem Toxicol 23, 945-947.

31. Julius AD, Davies MH \& Birt DF (1983) Toxic effects of dietary selenium in the Syrian hamster. Ann Nutr Metab 27, 296-305.

32. Canadian Council on Animal Care (1984) Guide to the Care and Use of Experimental Animals, vol. I and II. Ottawa: National Library of Canada.

33. Carr TP, Andersen CJ \& Rudel LL (1993) Enzymatic determination of triglyceride, free cholesterol and total cholesterol in tissue lipid extracts. Clin Biochem 26, 39-42.

34. Folch J, Lees M \& Sloane Stanley GH (1957) A simple method for the isolation and purification of total lipides from animal tissues. J Biol Chem 226, 497-503.

35. Cockell KA, Wotherspoon ATL, Belonje B, et al. (2005) Limited effects of combined dietary copper deficiency: iron overload on oxidative stress parameters in rat liver and plasma. J Nutr Biochem 16, 750-756.

36. Yu H, Pandit B, Klett E, et al. (2003) The rat STSL locus: characterization, chromosomal assignment, and genetic variations in sitosterolemic hypertensive rats. BMC Cardiovasc Disord 3, 4.

37. Shimomura I, Bashmakov Y, Shimano H, et al. (1997) Cholesterol feeding reduces nuclear forms of sterol regulatory element binding proteins in hamster liver. Proc Natl Acad Sci U S A 94, 12354-12359.

38. National Center for Biotechnology Information. Basic Local Alignment Search Tool. http://www.ncbi.nlm.nih.gov/blast/ Blast.cgi (accessed March 2007 and May 2009).

39. Chijiiwa K \& Nakayama F (1988) Simultaneous microanalysis of bile acids and cholesterol in bile by glass capillary column gas chromatography. J Chromatogr 431, 17-25.
40. Batta AK, Salen G, Rapole KR, et al. (1998) Capillary gas chromatographic analysis of serum bile acids as the $n$-butyl ester-trimethylsilyl ether derivatives. J Chromatogr 706, $337-341$.

41. Batta AK, Salen G, Rapole KR, et al. (1999) Highly simplified method for gas-liquid chromatographic quantitation of bile acids and sterols in human stool. J Lipid Res 40, 1148-1154.

42. SAS USA release 9·1, 1989-1996 Cary, NC: SAS Institute Inc.

43. Horton JD, Cuthbert JA \& Spady DK (1995) Regulation of hepatic 7 alpha-hydroxylase expression and response to dietary cholesterol in the rat and hamster. J Biol Chem 270, 5381-5387.

44. Yu L, Gupta S, Xu F, et al. (2005) Expression of ABCG5 and ABCG8 is required for regulation of biliary cholesterol secretion. J Biol Chem 280, 8742-8747.

45. Berge KEH, Tian GA, Graf L, et al. (2000) Accumulation of dietary cholesterol in sitosterolemia caused by mutations in adjacent ABC transporters. Science 290, 1771-1775.

46. Brown JM \& Yu L (2010) Protein mediators of sterol transport across intestinal brush border membrane. Subcell Biochem 51, 337-380.

47. Wolf NM, Mueller K, Hirche F, et al. (2010) Study of molecular targets influencing homocysteine and cholesterol metabolism in growing rats by manipulation of dietary selenium and methionine concentrations. Br J Nutr 104, 520-532.

48. Chen ZC, Shin SJ, Kuo KK, et al. (2008) Significant association of ABCG8:D19H gene polymorphism with hypercholesterolemia and insulin resistance. J Hum Genet $\mathbf{5 3}$, $757-763$.

49. Dieter MZ, Maher JM, Cheng X, et al. (2004) Expression and regulation of the sterol half-transporter genes ABCG5 and ABCG8 in rats. Comp Biochem Physiol 139, 209-218.

50. Dujovne CA, Ettinger MP, McNeer JF, et al. (2002) Efficacy and safety of a potent new selective cholesterol absorption inhibitor ezetimibe, in patients with primary hypercholesterolemia. Am J Cardiol 91, 1092-1097.

51. Kim JK \& Combs GF Jr (1997) Effects of selenium on colonic fermentation in the rat. Biol Trace Elem Res 56, 215-224.

52. Spady DK \& Dietschy JM (1983) Sterol synthesis in vivo in 18 tissues of the squirrel monkey, guinea pig, rabbit, hamster, and rat. J Lipid Res 24, 303-315.

53. Horton JD, Goldstein JL \& Brown MS (2002) SREBPs: activators of the complete program of cholesterol and fatty acid synthesis in the liver. J Clin Invest 109, 1125-1131.

54. Lund E \& Björkhem I (1995) Role of oxysterols in the regulation of cholesterol homeostasis: a critical evaluation. Acc Chem Res 28, 241-249.

55. Kong WJ, Liu J \& Jiang J-D (2006) Human low-density lipoprotein receptor gene and its regulation. J Mol Med $\mathbf{8 4}$, 29-36.

56. Mueller AS, Klomann SD, Wolf NM, et al. (2008) Redox regulation of protein tyrosine phosphatase $1 \mathrm{~B}$ by manipulation of dietary selenium affects the triglyceride concentration in rat liver. J Nutr 138, 2328-2336.

57. Shimizu S, Ugi S, Maegawa H, et al. (2003) Protein tyrosine phosphatase $1 \mathrm{~B}$ as new activator for hepatic lipogenesis via sterol regulatory element-binding protein-1 gene expression. J Biol Chem 278, 43095-43101.

58. Stranges S, Laclaustra M, Ji C, et al. (2009) Higher selenium status is associated with adverse blood lipid profile in British adults. J Nutr 140, 81-87. 